\title{
CME Diabetes Medicine (127352): self-assessment questionnaire
}

\author{
Authors: Edited by Tahseen Chowdhury and Kate Evans
}

\section{SAQs and answers are ONLINE for RCP fellows and} collegiate members

\section{Format}

Candidates are asked to choose the best answer from the five possible answers. This best of five format is used in many medical examinations; however, the questions are not intended to be representative of those used in the MRCP(UK) Part 1 or Part 2 Written Examinations.

\section{The answering process}

1 Go to www.rcplondon.ac.uk/SAQ

2 Log on using your usual RCP username and password

3 Select the relevant $\mathrm{CME}$ question paper

4 Answer all 10 questions by selecting the best answer from the options provided

5 Once you have answered all the questions, click on Submit

\section{Registering your external CPD credits}

Carrying out this activity allows you to claim two external CPD credits. These will be automatically transferred to your CPD diary, where you can review the activity and claim your points.

1. A 54-year-old man with adult polycystic kidney disease underwent a deceased donor renal transplant 2 days previously. He had no known past history of diabetes. He was noted to have fasting glucose of $5-8 \mathrm{mmol} / \mathrm{L}$, and 2 hour post evening meal glucose of $16-20 \mathrm{mmol} / \mathrm{L}$. He was well, and eating and drinking on the ward.

\section{Which of the following is the most appropriate management?}
(a) Empagliflozin $10 \mathrm{mg}$ once daily
(b) Fasting acting (eg Novorapid ${ }^{\circledR}$ ) insulin with breakfast
(c) Gliclazide $80 \mathrm{mg}$ twice daily
(d) Metformin 500 mg twice daily
(e) Neutral protamine hagedorn insulin (eg Humulin $\mathrm{I}^{\circledR}$ ) 10 units in the morning

2. A 44-year-old South Asian woman was awaiting a cardiac transplant for dilated cardiomyopathy. She had a previous history of gestational diabetes, and was overweight, with a strong family history of type 2 diabetes. Recent oral glucose tolerance test showed impaired glucose tolerance.

Which of the following immunosuppressants is most likely to cause post-transplant diabetes mellitus?
(a) Azathioprine
(b) Belatacept
(c) Ciclosporin
(d) Mycofenylate mofetil
(e) Tacrolimus

3. A 35-year-old woman with autoimmune hepatitis was being assessed for liver transplantation.

Which of the following infections is most likely to increase her risk of developing post-transplant diabetes mellitus?
(a) Hepatitis A
(b) Hepatitis B
(c) Hepatitis C
(d) Hepatitis D
(e) Hepatitis $\mathrm{E}$

4. A 35 year-old African-Caribbean man with a body mass index (BMI) of 32 (no prior history of diabetes) presented with a 4-week history of polyuria and increased thirst. Random plasma glucose was $28 \mathrm{mmol} / \mathrm{L}$, capillary ketones $4.5 \mathrm{mmol} / \mathrm{L}$ (normal reading $<0.6 \mathrm{mmol} / \mathrm{L}$ ), and venous $\mathrm{pH}$ 7.2. He was started on fixed rate intravenous insulin infusion (FRIII) and intravenous (IV) fluids.

\section{What is the underlying diagnosis and ongoing management required?}

(a) He definitely has type 1 diabetes and will need lifelong insulin treatment

(b) He has type 2 diabetes; FRIII should be stopped and metformin started

(c) He has type 2 diabetes but will need to stay on insulin long term

(d) The underlying diabetes diagnosis is not clear; FRIII should be continued until diabetic ketoacidosis (DKA) resolved, and then seek specialist advice on long-term management

(e) The underlying diabetes diagnosis is not clear; FRIII should be stopped immediately and blood glucose levels monitored 
5. A 52-year-old woman was diagnosed with type 2 diabetes 2 years ago and initially treated with metformin. Due to rising $\mathrm{HbA1c}$, she was started on empagliflozin 8 weeks ago. She presented to emergency department with 3 days of increasing lethargy, nausea and vomiting. Capillary glucose levels have been between 12-18 mmol/L.

\section{What is the diagnosis and treatment required?}

(a) Capillary ketones should be checked, and if elevated, she should be given intravenous fluids and started on FRIII. Empagliflozin and metformin should both be permanently discontinued

(b) Capillary ketones should be checked, and if elevated, she should be given intravenous fluids and started on FRIII. Specialist review is indicated, and the diagnosis of type 2 diabetes should be reviewed

(c) Her symptoms are unlikely to be secondary to empagliflozin as this was started 2 months ago

(d) She is likely to have gastroenteritis and does not need admission to hospital if she can maintain fluid intake

(e) To exclude DKA, she should have an immediate check for urinary ketones

6. A 17-year-old girl diagnosed with type 1 diabetes at the age of 12, presented with her second episode of DKA in the past 12 months. She is on a basal-bolus subcutaneous (SC) insulin regimen with novorapid and levemir. She was started on FRIII and IV fluids.

\section{What should her ongoing management consist of?}

(a) Before discharge, she should have specialist review of injection technique / blood glucose monitoring / equipment / sites and to reinforce sick day rules

(b) Both SC novorapid and levemir should be temporarily discontinued while she has DKA due to reduced tissue perfusion causing unpredictable SC insulin absorption

(c) If she is on the contraceptive pill, it is not necessary to do a pregnancy test

(d) Once her glucose levels are under $10 \mathrm{mmol} / \mathrm{L}$, IV treatment can stop and she can be discharged

(e) Recurrent presentations with DKA indicate that her SC insulin doses need increasing

7. Women with diabetes who are planning pregnancy, should be supported to aim for an $\mathrm{HbA1c}$ below which of the following values?
(a) $38 \mathrm{mmol} / \mathrm{mol}(5.6 \%)$
(b) $43 \mathrm{mmol} / \mathrm{mol}(6.1 \%)$
(c) $48 \mathrm{mmol} / \mathrm{mol}(6.5 \%)$
(d) $53 \mathrm{mmol} / \mathrm{mol}(7.0 \%)$
(e) $58 \mathrm{mmol} / \mathrm{mol}(7.5 \%)$

8. According to the National Institute for Health and Care Excellence guidance, which one of the following is not an indication to screen for gestational diabetes mellitus?

(a) BMI $>30 \mathrm{~kg} / \mathrm{m}^{2}$

(b) Family history of diabetes (first degree relative)

(c) Minority ethnic family origin with a high prevalence of diabetes

(d) Previous macrosomic baby weighing $>4.0 \mathrm{~kg}$

(e) Previous gestational diabetes mellitus

9. A 35-year-old woman, pregnant for the first time, has not yet delivered and has been recently diagnosed with gestational diabetes. She has been given advice on diagnosis and exercise and has been monitoring her blood glucose (mmol/L).

$\begin{array}{lllll}\text { Day } & \text { Fasting } & \begin{array}{l}\text { 1h post } \\ \text { breakfast }\end{array} & \begin{array}{l}\text { 1h post } \\ \text { lunch }\end{array} & \begin{array}{l}\text { 1h post } \\ \text { evening } \\ \text { meal }\end{array} \\ 1 & 4.5 & 6.7 & 6.8 & 5.8 \\ 2 & 5.2 & 8.4 & 7.1 & 6.3 \\ 3 & 4.7 & 8.0 & 5.8 & 5.9 \\ 4 & 5.0 & 8.1 & 6.5 & 6.2\end{array}$

Based on her results given in the table above, which of the following is the most appropriate next treatment?

(a) Humulin I 4 units once daily with breakfast

(b) Metformin 500 mg once daily with breakfast

(c) Metformin $500 \mathrm{mg}$ once daily with evening meal

(d) Metformin $500 \mathrm{mg}$ twice daily (breakfast and evening meal)

(e) Novorapid 4 units once daily with breakfast

10. Concerning liraglutide, which of the following is true?
(a) It is a glycoprotein-1 receptor agonist
(b) It can cause pancreatitis
(c) It is an oral glucose-lowering agent
(d) It lowers $\mathrm{HbA} 1 \mathrm{c}$ by about $2-5 \%$
(e) It is often associated with weight gain

\section{CME Palliative Medicine SAQ Answers to the CME SAQ published in Clinical Medicine in July 2019 \\ $\begin{array}{llllllllll}\text { Q1 } & \text { Q2 } & \text { Q3 } & \text { Q4 } & \text { Q5 } & \text { Q6 } & \text { Q7 } & \text { Q8 } & \text { Q9 } & \text { Q10 }\end{array}$

(d) (a) (a) (e) (d) (c) (e) (b) (b) (c)

